Remane - Emil Fischer 


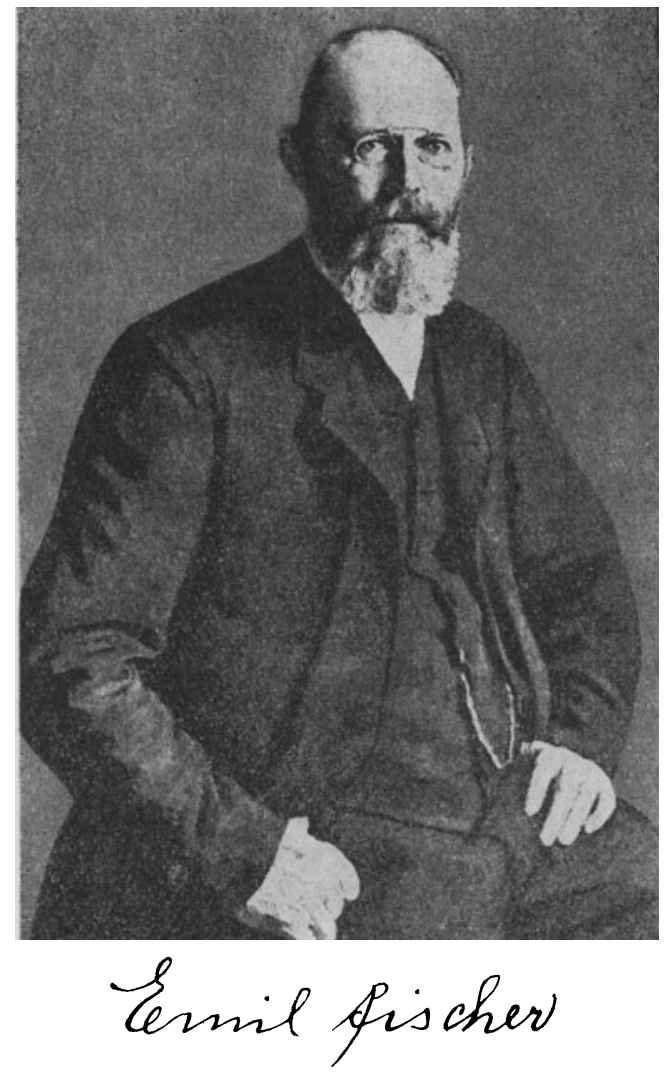

1 Emil Fischer (9. 10. 1852-15. 7. 1919)

Porträt von Emil Fischer nach einem Gemälde von Schulte im Hofe [B 1] 
Biographien

hervorragender Naturwissenschaftler,

\section{Emil Fischer}

Dr. sc. nat. Horst Remane, Leipzig

Mit 13 Abbildungen

\section{霄 \\ แurnace}

Springer Fachmedien Wiesbaden GmbH 1984 


\section{Herausgegeben von}

D. Goetz (Potsdam), I. Jahn (Berlin). E. Wächtler (Freiberg), H. Wußing (Leipzig)

Verantwortlicher Herausgeber: D. Goetz

ISBN 978-3-322-00627-1 ISBN 978-3-322-86700-1 (eBook)

DOI 10.1007/978-3-322-86700-1

(C) Springer Fachmedien Wiesbaden 1984

Ursprünglich erschienen bei BSB B.G. Teubner Verlagsgesellschaft, Leipzig 1984

1. Auflage

VLN 294-375/63/84 - LSV 1208

Lektor: Hella Müller

Gesamtherstellung: Elbe-Druckerei Wittenberg IV-28-1-738

Bestell-Nr. 6661947

00480 


\section{Inhalt}

Emil Fischer und seine Zeit 6

Kindheit und Jugend 10

W' issenschaftlicher Werdegang 13

Studium und Promotion 13

Die Entdeckung des Phenylhydrazins 16

Baeyer-Schüler in München (1875-1882) 17

Ordinarius in Erlangen und Würzburg 21

Erlangen (1882-1885) 21

Würzburg (1885-1892) 23

Arbeiten zur Chemie der Kohlenhydrate

Ehe und Familie 33

Emil Fischer in Berlin 37

Ordinarius in Berlin 37

Forschungen zur Chemie der Aminosäuren, Polypeptide und

Proteine 42

Emil Fischer als Hochschullehrer und Wissenschaftsorganisator 47

Die Zeit des ersten Weltkrieges 55

Untersuchungen über Depside, Flechtenstoffe und Gerbstoffe sowie über Glykoside $\quad 58$

Krankheit und Tod 63

Chronologie 68

Literatur 71

Personenregister $\quad 74$ 